\title{
Experimental dynamic analysis of traffic seismicity effect on historical building
}

\author{
Daniel Papan ${ }^{1, *}$,Zuzana Papanova ${ }^{1}$, and Katarina Krkoskova ${ }^{2}$ \\ ${ }^{1}$ University of ZilinaTechnology, Faculty of Civil Engineering, Zilina, Slovakia \\ ${ }^{2}$ HILTI Slovakia s.r.o, Zilina, Slovakia
}

\begin{abstract}
Nowadays, rising intensity of traffic is significant effect on entire world, because the endanger risk of adjacent buildings rises. Endanger risk is caused by traffic vibrations spreading through the bedrock, i.e. by traffic seismicity. Historical buildings are specific group of structures, which are especially sensitive on traffic seismicity effects. The aim of this article is experimental dynamic analysis of traffic seismicity effect on Traction substation historical building in Horný Smokovec, district Poprad in Slovakia. This structure is directly exposed to road and rail traffic effects. The experimental measurements of vibration levels were implemented, whose outputs had been vibration acceleration time records on this structure. In all experimental measurements, vibration levels and its transmission through the bedrock were detected, because of train crossing effecting on tower part of object (because the tower part is nearby the railway and it is also the highest place on building) and vehicle crossing. The study of dynamic interaction is implemented within the amplitude analysis. The spectral analysis and frequency transmission is presented in the paper within the frequency analysis. The evaluation of implemented traffic seismicity experimental dynamic analysis effecting on the traction substation object is the end part of analysis.
\end{abstract}

Keywords: traffic seismicity, experimental dynamic analysis, experimental measurements

\section{Introduction}

Vibrations induced by traffic increasingly effect the environment. This element brings oneself to noting more, so it also appears in latest studies [1]. Nowadays, despite the importance of the issue, the unforcedness about vibrations induced by traffic and their effects on historical buildings is still limited. The aim of this article is dynamic experimental analysis of Traction Substation historical building due to traffic seismicity in Horný Smokovec district Poprad. This structure is directly exposed to road and rail traffic effects. Two experimental measurements were implemented on this object, whereby 12

${ }^{*}$ Corresponding author: daniel.papan@,fstav.uniza.sk 
accelerometers of low frequency seismic type and measuring and evaluating technique by company Brüel \& Kjær were used. Measurements outputs are vibration acceleration time records due to train crossing and middle heavy vehicle crossing. Experimental measurements evaluation consists of amplitude and frequency analysis of vibration acceleration time records. Results of amplitude analysis are vibration velocity effective values, whereby the maximal ones of them were assessed according to [2]. The dynamic interaction coefficient $k_{D I}$ describing the character of vibration transmission type from the source to the object was also detected for these values. Within the frequency analysis, vibration acceleration power spectral densities and frequency response functions, which describe what frequency range is typical for this type of dynamic load, are presented. The end part of analysis is evaluation of implemented experimental dynamic analysis of traffic seismicity effecting on Traction Substation object.

\section{Theoretical basis of identified issue and experimental equipment}

The parasiesmic effects caused the vibration of the structures and it can be analysed by random vibration approach mainly in evaluation areas as follows [9]:

- The time domain (signal in time $-x(t)$ ),

Effective value (mean value, max value, min value, ect.), root mean square ( $r m s$ )

$$
\sigma_{x}=R M S=x_{e f}=\sqrt{\frac{1}{T}} \int_{0}^{T} x(t)^{2} d t .
$$

- Correlation (correlation between two random processes),

Autocorrelation function (cross correlation function, ect.)

$$
R_{x x}(\tau)=\lim _{T \rightarrow \infty} \frac{1}{T} \int_{0}^{T} x(t) x(t+\tau) d t .
$$

- The frequency domain (harmonic analysis),

- Spectral evaluation (transformation time processes to frequency domain),

Power Spectral Density (PSD)

$$
G_{x x}(f)=2 \int_{-\infty}^{\infty} R_{x x}(\tau) e^{-i 2 \pi f \tau} d t
$$

Coherency function

$$
\gamma_{x y}(f)^{2}=\frac{\left|G_{x y}(f)\right|^{2}}{G_{x x}(f) G_{y y}(f)} \leq 1 .
$$

Gain factor, Transfer function, Frequency Response Functions (FRF)

$$
H(\text { if })=\frac{G_{x y}(f)}{G_{x x}(f)} .
$$

- Probabilistic area (statistic parameters),

- Informatics (effective - determined signal in noise). 
These formulas are basic equations for further analysis in the paper. All applications of this theoretical formulation (continuous function of random effects) are transformed to the discrete domain. Discrete data are evaluated as random signal and they are processed as digitalized records of vibration accelerations in time. So the numerical tool Sigview was used as relevant analyzer for the experimental solutions.

For the data recording the powerful system PULSE were used. PULSE is a versatile, task-oriented system for noise and vibration analysis. It provides the platform for a range of PC-based measurement solutions from Brüel \& Kjær. A PULSE system consists of a PC with LAN interface, PULSE software, Windows ${ }^{\circledR} 2000$, XP or Windows Vista ${ }^{\circledR}$, Microsoft ${ }^{\circledR}$ Office and idea - based data acquisition front-end hardware.

A system can contain more than 300 input channels located in up to 10 front-ends. The input/ output conditioning modules perform signal conditioning and digitalize the transducer signals. Measured line for the case study was created from parallel modules connected set and the others components which are shown in Fig. 1.
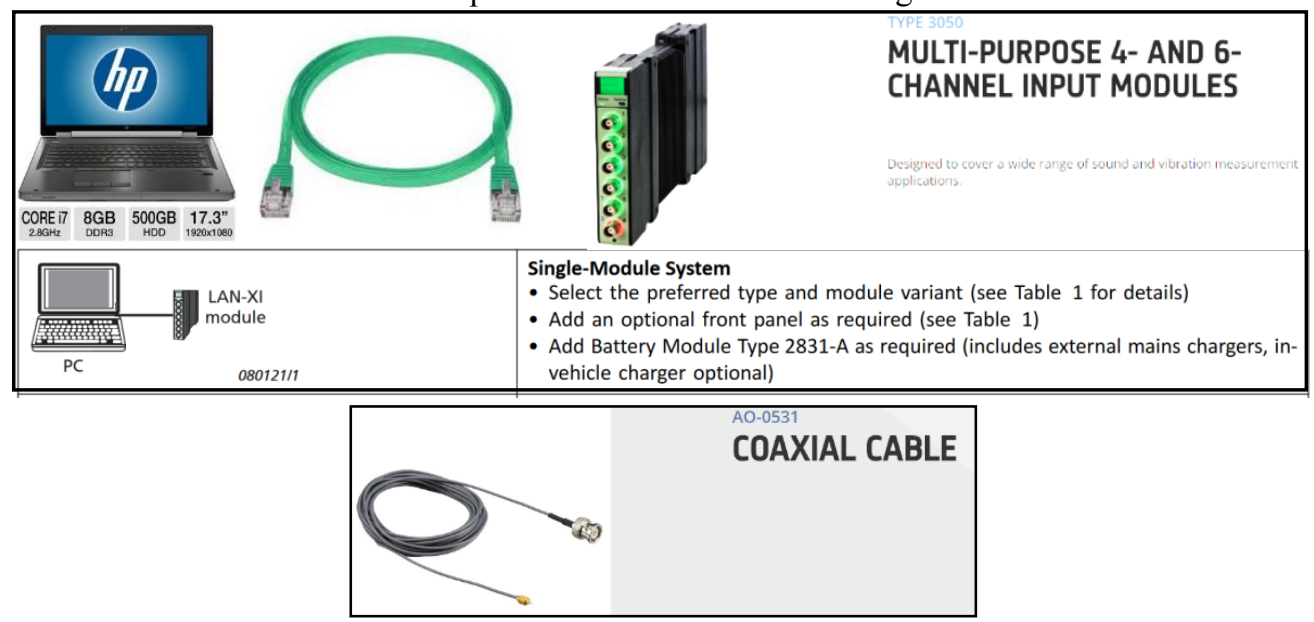

CCLD Accelerometer Types 4507 and 4508 CCLD TEDS Accelerometer Types 4507-B and Charge Accelerometer Types 4507-C and 4508-C

CCLD $^{*}$ Accelerometer Types 4507 and 4508 consist of a ThetaShear ${ }^{\circledR}$ accelerometer and a CCLD preamplifier in a lightweight titanium housing with integrated 10-32 UNF connectors. TEDS ${ }^{\dagger}$ version is also available. Types 4507-C and 4508-C are the charge types similar to the CCLD accelerometers but come without charge types sim
the preamplifier.

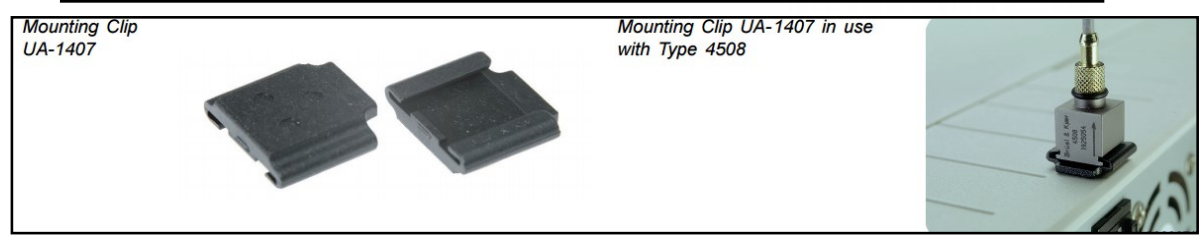

Fig. 1. Used measured tools Brüel \& Kjær with software PULSE included [11]

As the complex parameter evaluating technical seismicity impact the most effective is the concept based on Coefficient of dynamic interaction $\left(k_{D I}\right)$. The interaction of shear deformation surface waves with the foundation structure affect the transfer wave energy to the support structure [10]. For the purposes of technical diagnostics of vibration levels should be determined the coefficient of dynamic interaction $k_{D I}$ (respectively $k_{z}$ ). Dynamic 
interaction coefficient can be determined as the ratio of the value of the vibration energy absorbed structure (effective level of vibration of the structure $v_{K}$ ) and the incoming vibration energy of the subsoil (effective level of vibrations subsoil $v_{P}$ ). Energy balance is best and easiest to express using effective values of vibration amplitudes ( $r m s$ - dynamic process values integral).

In the present case study the coefficient of dynamic interaction were determined used the results of spectral analysis.

$$
k_{D I}=\frac{v_{k, R M S}}{v_{k, R M S}} .
$$

Due to the interaction of waves in the soil (wave reflection, wave interference, etc.) transfer coefficient generally takes the value $k_{D I}<1,0$. On this basis, it is necessary to calculate the expected values of technical seismicity vibration effect at the base joints multiply $k_{D I}$ value. In the practical experiment, the ISM (Impulse Seismic Method) and the technical seismicity results can be applied to expression $v_{R M S}$ and $k_{D I}$ values (Tab. 3).

\section{Characteristics of Traction Substation historical building}

Traction Substation is located in Horný Smokovec on the railway Poprad - Starý Smokovec that is first source of vibration. It belongs to the list of national heritage buildings of Slovakia and it is registered as NHB 706-11673/0. It was built in Art Nouveau style ca. in 1912. The road II/537 leads nearby the structure and its traffic second source of vibration. Fig. 2
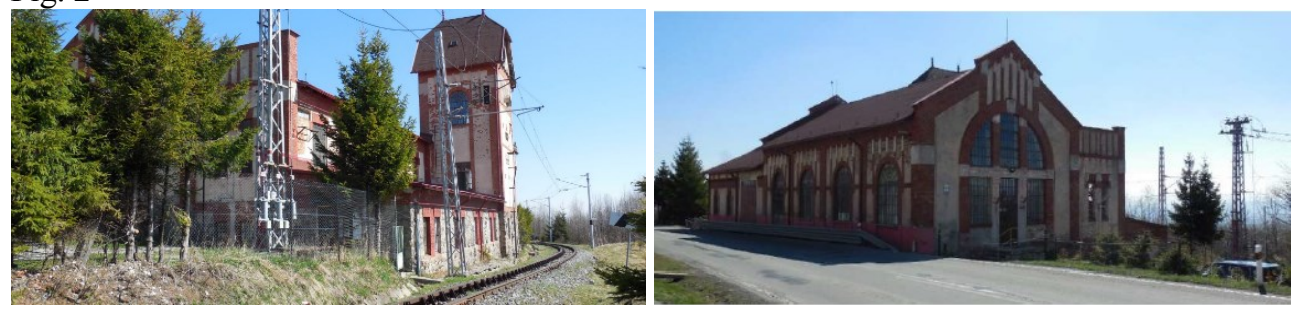

Fig. 2. Traction Substation views from the railway and the road.

\section{Preparation and process of experimental measurements}

Experimental measurement was separated in two parts, whereby the vibration level from two different vibration sources was measured in both parts. Vibration level due to road traffic, type and character of vibration transmission from the road to the object was measured in first part. Accelerometers were located it the area between the road and the object. Second part of measurement includes the vibration level measurement due to rail traffic, also the type and character of vibration transmission from the railway to the object. Accelerometers were placed between the railway and the object. Fig. 3. 


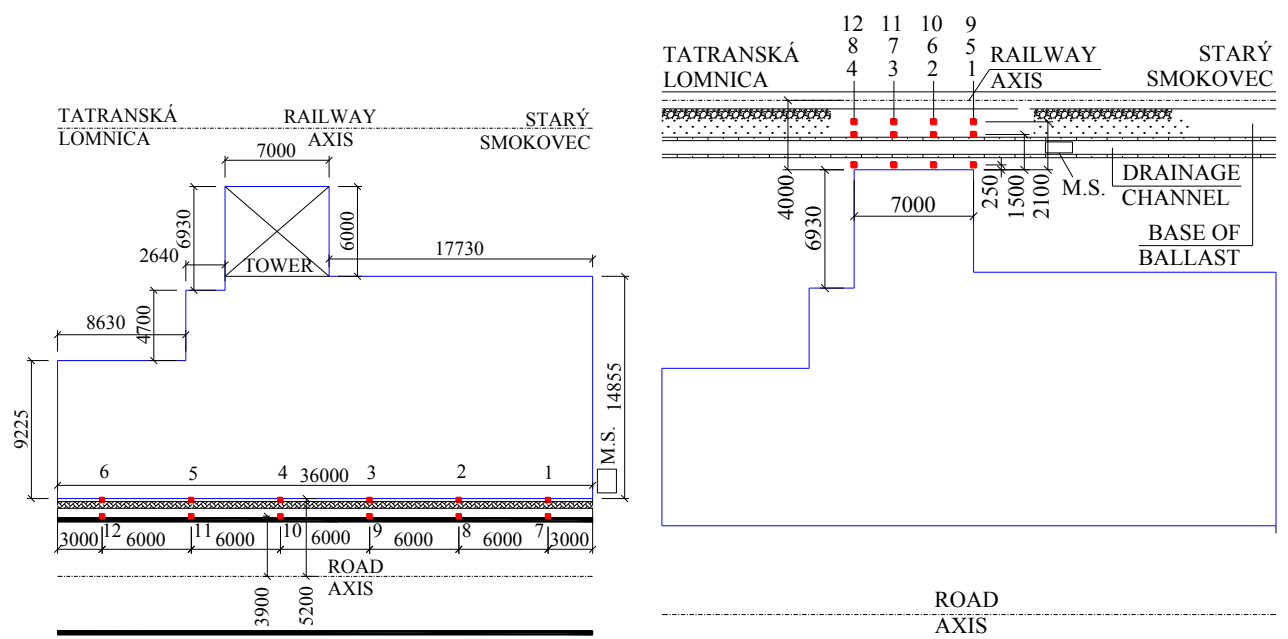

Fig. 3. Accelerometers positions in first and second part of measurement.

\section{Experimental measurements results}

Outputs of both experimental measurements are vibration acceleration time records in measured points. The values from these records were analyzed in the program for signal analyses, Sigview.

\section{- Time domain:}

Within the experimental measurements evaluation in time domain were detected these values by measured vibration acceleration analysis:

$$
\begin{aligned}
& a_{R M S}[\mathrm{~m} / \mathrm{s} 2] \quad-\quad \text { vibration acceleration effective value } \\
& a_{M I N}, \operatorname{MAX}[\mathrm{m} / \mathrm{s} 2] \quad-\quad \text { minimal / maximal vibration acceleration values } \\
& v_{R M S}[\mathrm{~m} / \mathrm{s}] \quad-\quad \text { vibration velocity effective value and compared with limit } \\
& \text { Standard value } v_{e f}[\mathrm{~m} / \mathrm{s}] \text { in [2] }
\end{aligned}
$$

\section{- Frequency domain:}

$\operatorname{PSD}(a)\left[\left(\mathrm{m} / \mathrm{s}^{2}\right)^{2} / \mathrm{Hz}\right]-\quad$ Power spectral density of vibration acceleration

FRF (a) [-] $\quad-$ Frequency response function of vibration acceleration

\subsection{Experimental measurement no. 1 - results}

\subsubsection{Amplitude analysis}

Maximal effective vibration acceleration value was attained at the vibration source near the measured point 11 , and that during the bus vehicle crossing, $a_{R M S}=0.0308 \mathrm{~m} / \mathrm{s}^{2}$ that accords with vibration velocity effective value $v_{R M S}=5.34 \mathrm{E}-4 \mathrm{~m} / \mathrm{s}$. Maximal effective vibration acceleration value was attained at the object in the measured point $4, a_{R M S}=$ $0.0100 \mathrm{~m} / \mathrm{s}^{2}$ that accords with vibration velocity effective value $v_{R M S}=8.94 \mathrm{E}-5 \mathrm{~m} / \mathrm{s}$. Tab. 1 . This value is assessed according to [2]. 
Table 1. Analyzed values of $a_{R M S}, a_{M A X}, a_{M I N}$ in measurement no. 1 (road - object)

\begin{tabular}{|c|c|c|c|}
\hline M1 & \multicolumn{3}{|c|}{$a i\left[\mathrm{~m} / \mathrm{s}^{2}\right]$} \\
\hline Point & $a_{R M S}$ & $a_{M A X}$ & $a_{M I N}$ \\
\hline 1 & 0.0022 & 0.0087 & -0.0067 \\
\hline 2 & 0.0085 & 0.0258 & -0.0272 \\
\hline 3 & 0.0092 & 0.0315 & -0.0255 \\
\hline 4 & $\mathbf{0 . 0 1 0 0}$ & 0.0312 & -0.0326 \\
\hline 5 & 0.0067 & 0.0229 & -0.0310 \\
\hline 6 & 0.0052 & 0.0200 & -0.0191 \\
\hline 7 & 0.0123 & 0.0401 & -0.0456 \\
\hline 8 & 0.0234 & 0.0779 & -0.0723 \\
\hline 9 & 0.0204 & 0.0589 & -0.0625 \\
\hline 10 & 0.0293 & 0.0765 & -0.0322 \\
\hline 11 & $\mathbf{0 . 0 3 0 8}$ & 0.0338 & -0.0227 \\
\hline 12 & 0.0224 & 0.0767 & -0.0876 \\
\hline
\end{tabular}

The Traction Substation building can be typed to resistance class "A" according to Table NB.8.2. in [2] and also to significance class of buildings "II" according to Table NA.1 in [3]. Limit value of effective vibration velocity $v_{e f}=0.7 \mathrm{~mm} / \mathrm{s}$ responses to this classification. The value of effective vibration velocity detected by analysis is $v_{R M S}=$ $0.0894 \mathrm{~mm} / \mathrm{s}$. From these values results that this object is not needed to be analyzed in terms of I. ultimate state due to rules in [2].

\subsubsection{Frequency analysis}

The part of frequency range up to $15 \mathrm{~Hz}$ can be attributed to bus vehicle vibration due to [4], [5] and other references. Remaining part of frequency range from $15 \mathrm{~Hz}$ up to $75 \mathrm{~Hz}$ can be attributed to road pavement vibration due to [6], [7] and other ones. Analysis is aimed to frequency range $15-120 \mathrm{~Hz}$.

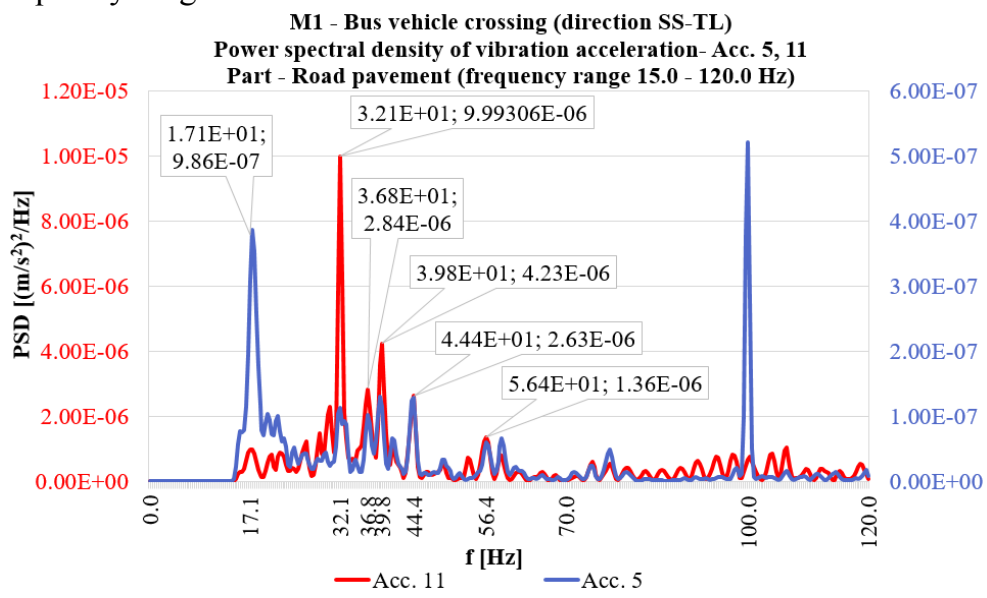

Fig. 4. PSD (a) of road pavement in frequency range $15-120 \mathrm{~Hz}$, Acc. 5, 11. 


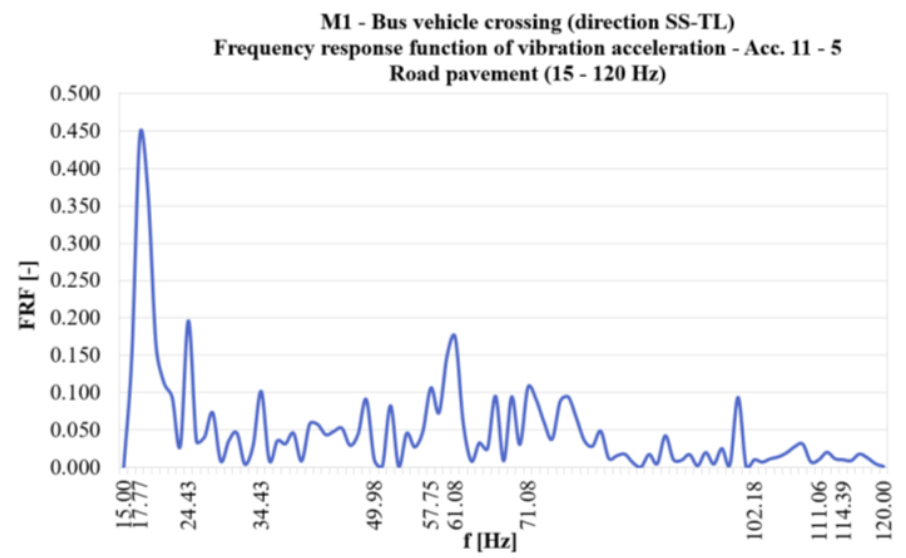

Fig. 5. FRF ( $a$ ) of road pavement in frequency range $15-120 \mathrm{~Hz}$ (between the road and the object).

Dominant frequencies characterizing vehicle vibrations are $6.6 \mathrm{~Hz}$ and $13.3 \mathrm{~Hz}$. The area of dominant frequencies describing road pavement vibrations is $17-30 \mathrm{~Hz}$.

\subsection{Experimental measurement no. 2 - results}

\subsubsection{Amplitude analysis}

Maximal value of effective vibration acceleration was attained in point no. 10, $a_{R M S}=$ $0.1840 \mathrm{~m} / \mathrm{s}^{2}$, which accords with $v_{R M S}=5.63 \mathrm{E}-4 \mathrm{~m} / \mathrm{s}$. The value of $a_{R M S}=0.0478 \mathrm{~m} / \mathrm{s}^{2}$ was attained in point no. 4 nearby the tower part of object. Tab. 2 . This value accords with $v_{R M S}$ $=1.34 \mathrm{E}-4 \mathrm{~m} / \mathrm{s}$ that is assessed in next step due to [2].

Table 2. Analyzed values of $a_{R M S}, a_{M A X}, a_{M I N}$ in measurement no. 2 (road - object)

\begin{tabular}{|c|c|c|c|}
\hline M2 & \multicolumn{3}{|c|}{ ai $[\mathrm{m} / \mathrm{s} 2]$} \\
\hline Point & $a_{R M S}$ & $a_{M A X}$ & $a_{M I N}$ \\
\hline 1 & 0.0256 & 0.1139 & -0.1205 \\
\hline 2 & 0.0301 & 0.1376 & -0.1156 \\
\hline 3 & 0.0438 & 0.1655 & -0.1747 \\
\hline 4 & $\mathbf{0 . 0 4 7 8}$ & 0.2563 & -0.2828 \\
\hline 5 & 0.0792 & 0.5640 & -0.5013 \\
\hline 6 & 0.0903 & 0.4826 & -0.7300 \\
\hline 7 & 0.1046 & 0.6100 & -0.5391 \\
\hline 8 & 0.0868 & 0.4730 & -0.5892 \\
\hline 9 & 0.1760 & 0.8924 & -1.1091 \\
\hline 10 & $\mathbf{0 . 1 8 4 0}$ & 1.8521 & -1.6053 \\
\hline 11 & 0.1684 & 1.3148 & -1.2712 \\
\hline 12 & 0.1834 & 1.1371 & -1.5874 \\
\hline
\end{tabular}

Limit value of effective vibration velocity is $v_{e f}=0.7 \mathrm{~mm} / \mathrm{s}$. Analyzed value is $v_{R M S}=0.134$ $\mathrm{mm} / \mathrm{s}$. From these values results that this object is not needed to be analyzed in terms of $\mathrm{I}$. ultimate state due to rules in [2]. 


\subsubsection{Frequency analysis}

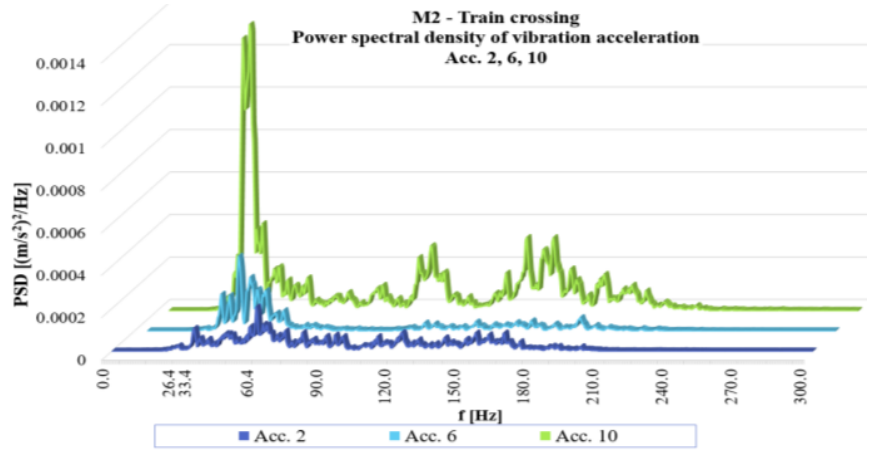

Fig. 6. PSD (a) of train crossing in M2 (between the railway and the object).

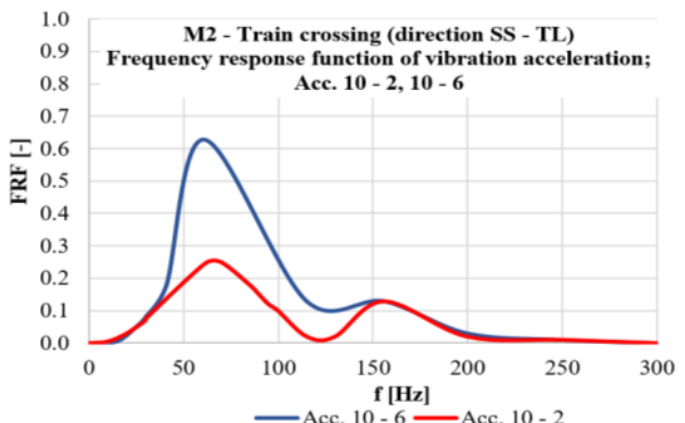

Fig. 7. FRF ( $a$ ) of train crossing in M2 (between the railway and the object).

These diagrams mean, that dominant frequencies are $30-50 \mathrm{~Hz}$ and $50-70 \mathrm{~Hz}$. Frequency range $30-50 \mathrm{~Hz}$ dominates near the rail, that accords with rail string vibration and rail sleepers vibration due to [8]. Frequency range $50-70 \mathrm{~Hz}$ dominates farther from the rail, so mostly directly nearby the tower part of object that accords with vibration of rail sleepers - base of ballast system and base of ballast - bedrock system due to [8].

The examples of the frequency domain analysis are presented in Fig. 4 - Fig. 7. Tab. 3 shows analyzed values of $k_{D I}$ in measurements.

Table 3. Analyzed values of $k_{D I}$ in measurements

\begin{tabular}{|c|c|c|c|}
\hline \multicolumn{4}{|c|}{ Road traffic } \\
\hline Points & $a_{R M S, i}$ & $a_{R M S, j}$ & $k_{D I}$ \\
\hline $1 \ldots 7$ & 0.0022 & 0.0123 & 0.1788 \\
\hline $2 \ldots 8$ & 0.0085 & 0.0234 & 0.3632 \\
\hline $3 \ldots 9$ & 0.0092 & 0.0204 & 0.4509 \\
\hline $4 \ldots 10$ & 0.0100 & 0.0293 & 0.3412 \\
\hline $5 \ldots 11$ & 0.0067 & 0.0308 & 0.2175 \\
\hline $6 \ldots 12$ & 0.0052 & 0.0224 & 0.2321 \\
\hline \multicolumn{4}{|c|}{ Railway traffic } \\
\hline $1 \ldots 5$ & 0.0022 & 0.0067 & 0.3283 \\
\hline $2 \ldots 6$ & 0.0085 & 0.0052 & 0.6110 \\
\hline $3 \ldots 7$ & 0.0092 & 0.0123 & 0.7411 \\
\hline $4 \ldots 8$ & 0.0100 & 0.0234 & 0.4272 \\
\hline
\end{tabular}




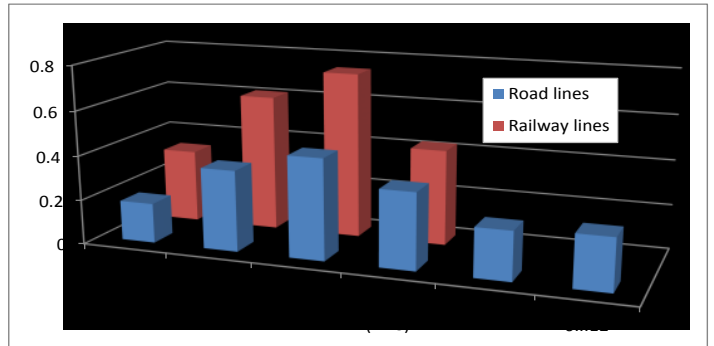

Fig. 8. Coefficient of dynamic interaction $k_{D I}$.

\section{Conclusions}

The authors were guided by the literature in this field during completing this contribution and solving issues during analyses. (e.g. [12])

The main aim of the analysis was to identify the spectral characteristics of selected historical structure and response due to microtremor effect involved by roadway and railway traffic. For this building the dominant frequency bands were identified which indicates natural frequencies peaks. For this case study of the selected sensitive monumental building the frequency transfers functions (via spectral characteristics) were obtained. The vibration level which decreases depending on the distance from the vibration source was observed. This case study showed precision technique to obtain dominant frequency bands of the structure dynamic response for railway and for roadways excitation.

The vibrations problems near roads, railways and their propagation to the surroundings affect on buildings and comfort of people. Vibration levels increase in residential areas cause: increasing axle loads, speeds of vehicles with higher weight levels, quality of surface transport routes and also residential quarters situating closer to traffic road.

Analysis of the interaction dynamic process brings new knowledge that can be applied into the actual building structures design. It also can be used as the evaluation and prediction of the structural dynamic response due technical seismicity.

The experimental procedure is relevant for technical practice. Spectral analysis can confirm viscoelastic action of soil structure. Comparison of different soil-structure spectral parameters in the interaction area confirms dominant bands from the traffic effects but also can identify investigated structure natural frequencies with attenuation.

Furthermore, the methodology of $k_{D I}$ can be used as the introduction and its practical application in civil engineering practice design and assessing of technical seismicity vibration intensity affecting on structures. The results obtained from the dynamic diagnosis confirmed the relevance of this coefficient introduction into the practice. Even if the Slovak standard limits were not exceed based on the $k_{D I}$ conception further and more describing parameters can be expressed (coefficient of basement inhomogeneity, structural health coefficients...)

\section{References}

1. M. Crispino, M. D'Apuzzo, R. Lamberti, G. Antonnuci, R. Constanzo,. Proceedings of the International Symposium on Environmental Impact of Road. Porto, 177-191. Road traffic induced vibrations in a field of investigation in the city of Naples (1999)

2. Eurocode 8. STN EN 1998-1/NA: Designing structures on seismic load. Part 1: General rules, Seismic loads and rules for buildings. National Appendix. 
3. Eurocode 8. STN EN 1998-2/NA: Navrhovanie konštrukcií na seizmickú odolnost'. Čast' 2: Mosty. Národná príloha. (Eng.: Designing structures on seismic resistance. Part 2: Bridges, National appendix.)

4. A. Galal, Frequency Response Considering Driver-seat. In: International Journal of Scientific Research Engineering \& Technology (IJSRET), ISSN 2278 - 0882 Vol.4, Issue 4, Car Dynamics using Quarter Model and Passive Suspension (2015)

5. J. Melcer, G. Lajcakova, Numerical Simulation of Vehicle Motion along the Road Structure. In: Roczniki Inżynierii Budowlanej - Zeszyt: Komisja Inżynierii Budowlanej Oddział Polskiej Akademii Nauk, Katowice, ISSN 1505-8425 (2012)

6. J. Bencat, D. Papan, Investigation of the microtremor due to road traffic means. In: Wplywy sejsmiczne i parasejsmiczne na budowe : X. Sympozjum. - Kraków: Institut Mechaniki Budowli Politechniki Krakowskej, (2003)

7. H. Zhao, L. Qin, J. Ling, Test and Analysis of Bridge Transducers for Harvesting Energy from Asphalt Pavement. In: International Journal of Transportation Science and Technology, Volume 4, Issue 1, 1 March (2015)

8. M. Moravcik, M. Moravcik, Mechanika železničných tratí. 3. diel Experimentálna analýza namáhania a pretvorenia komponentov trate. Žilina: Žilinská univerzita v Žiline, 2002. 220 s. ISBN 80-7100-985-7 (Eng.: Railway mechanics. Part 3. Experimental analysis of strain and displacement of railway elements.)(2002)

9. D. Papan, Paraseismic loading of bridge structures. In: Computational structures technology : proceedings of the eleventh international conference : Dubrovnik Croatia, Stirlingshire: Civil-Comp Press (2012)

10. Z. Papanova, Soil-structure dynamic interaction experimental analysis due to railway traffic In: GEOconference on science and technologies in geology, exploration, 14th International Multidisciplinary Scientific Geoconference SGEM (2014)

11. Electronic document: https://www.bksv.com/media/doc/bu0228.pdf

12. M. Maldonado, D. Le Houedec, Vibration induced by trams: Propagation, isolation and perception, Proc. 6th Intern. Conf. on Structural Dynamics: EURODYN 2005, Millpress, vol. 3, pn. 2047-2052 (2005) 